\title{
Intravitreal ranibizumab for the treatment of macular oedema associated with branch retinal vein occlusion 3 year results
}

\begin{abstract}
The three year results of intravitreal Ranibizumab treatment for macular oedema associated with Branch retinal vein occlusion between April 2014-March 2017 were audited.

Aim: The aim of our audit is to determine the visual acuity following treatment, frequency of injections and the percentage of eyes that have achieved defined visual acuity and driving vision. We also compared our results with major studies. It is a retrospective systematic analysis of data derived from Medisoft software.

Conclusion: Our patients had 20 letter improvements in mean visual acuity from baseline at 35 months of treatment this is comparable with RETAIN study, where there were 20.1 letter gains at 4 years. More than half of eyes treated achieved driving vision of over 70 letters. Our patients received an average 7 injections in the first year as compared to 8.4 in RETAIN study and 8.3 in BRAVO study. The results are comparable to major RCT studies.
\end{abstract}

Volume 7 Issue 3 - 2017

\author{
Niveditha Chittajallu, Priya Prakash \\ Ophthalmology department, Princess Alexandra Hospital, UK
}

Correspondence: Niveditha Chittajallu, Eye Unit, Princess Alexandra Hospital, Harlow, United Kingdom, Email nivedic.taj@gmail.com

Received: July 29, 2017 | Published: August 21, 2017

Keywords: ranibizumab, brvo, mean visual acuity, driving vision, retain study, bravo study

Abbreviations: NICE, national institute of clinical excellence; $\mathrm{PAH}$, princess alexandra hospital; T\&E, treat and extend; VA, visual acuity; BRAVO, branch retinal vein occlusion; RETAIN, the extended follow-up of patients with macular edema due to branch retinal vein occlusion or central retinal vein occlusion previously treated with intravitreal ranibizumab

\section{Introduction}

Ranibizumab for treating visual impairment caused by macular oedema secondary to Branch retinal vein occlusion was published by NICE in May 2013 and has been available to NHS patients since late 2013. We report our results for three years from April, 2014 to April, 2017 at Princess Alexandra Hospital (PAH), Harlow. The current regimen used at PAH is the Treat and Extend (T\&E), which was implemented following the update to the Ranibizumab license. The aim of our audit is to determine the visual acuity (VA) outcomes and injection frequency of intravitreal Ranibizumab in patients with BRVO treated. To assess percentage of people achieving defined visual outcome and achieving driving vision.

\section{Discussion}

\section{Methods}

Retrospective systematic review and analysis of patient data was carried by use of Medisoft software. It included the 3 year data between April 2014 and April 2017.

\section{Results}

All patients received intravitreal Ranibizumab initial loading dose of 5 injections or until stable VA for 3 visits followed by treat and extend regimen. A total of 101 patients and 103 injections were administered. 2 patients developed bilateral disease during the course of treatment. A total of 111, 317, 306 and 75 injections were administered during the years of 2014, 2015, 2016 and 2017 respectively (Figures 1\&2). Patients received an average of 7 injections in the first year, followed by 4 in the second year (Figure 3). The frequencies of visits are 9.4 in the first year and 6.9 in the second year (Figure 4).

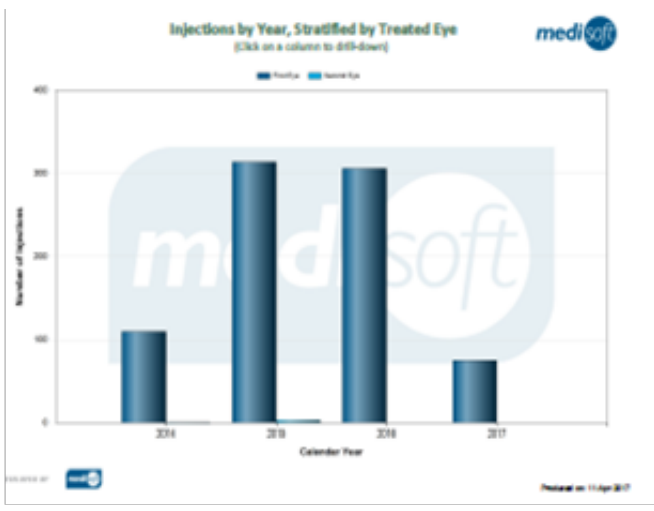

Figure I Injections by year.

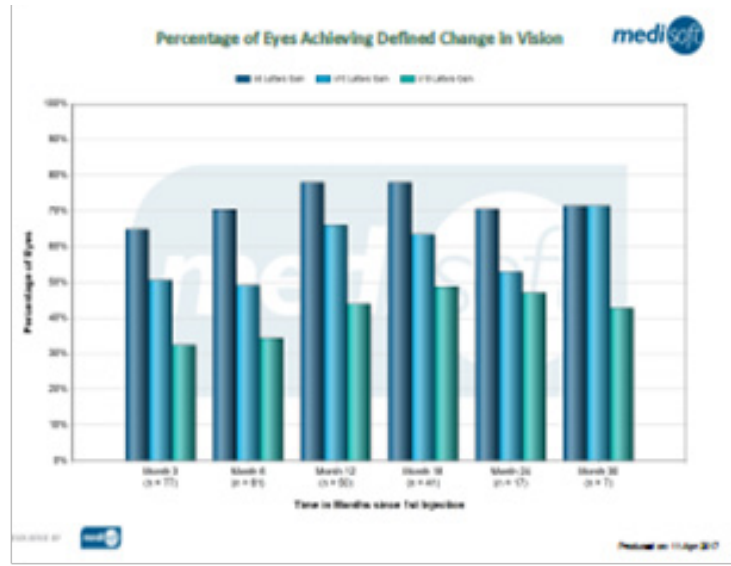

Figure 2 Proportion of eyes achieving definedVA. 


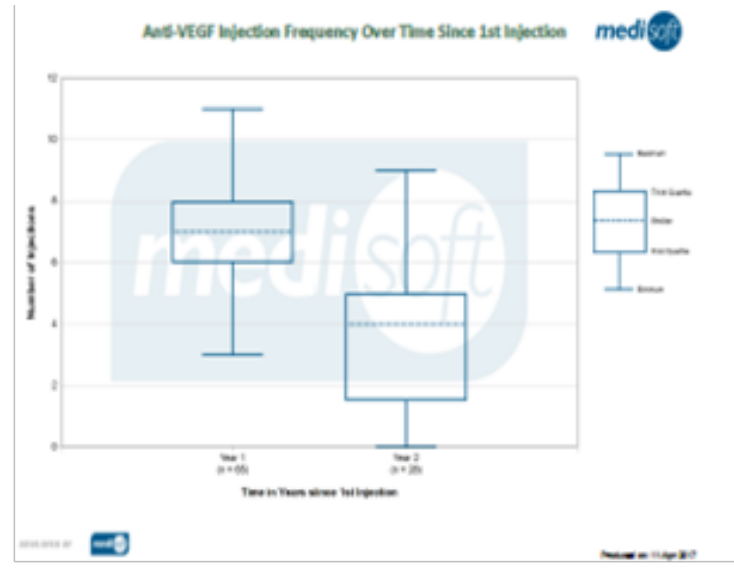

Figure 3 Injection frequency over time.

\section{Conclusion}

In RETAIN study; mean VA was 74.1 letters at 4 years, an improvement of 20.1 letters from baseline (mean baseline VA 54 letters) as compared to 20 letters from baseline (mean VA 55 to 75 letters) at 30 months in our study (Figures 5\&6) (Table 1). Mean

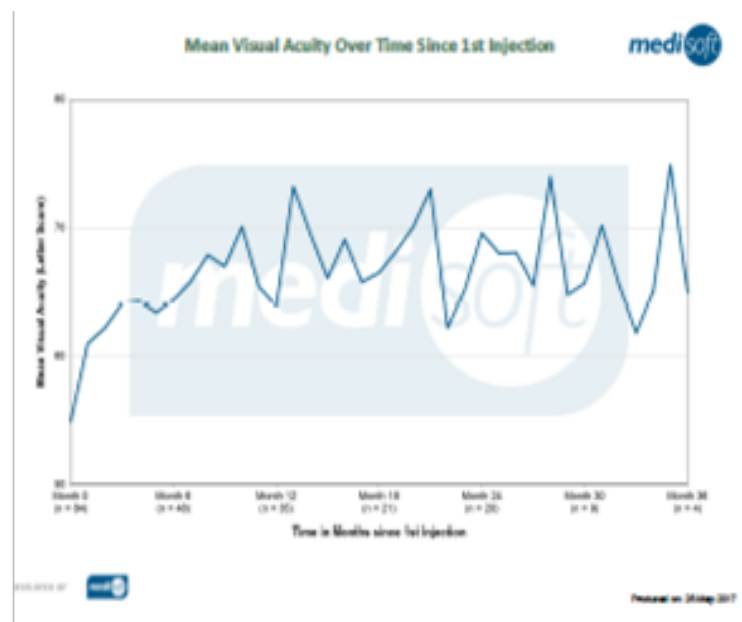

Figure 5 Mean VA over time.

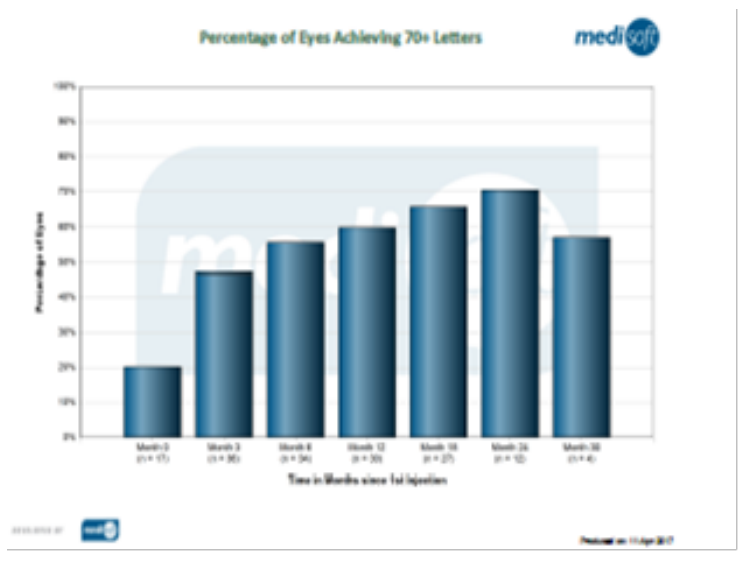

Figure 6 Proportion of eyes achieving driving VA.

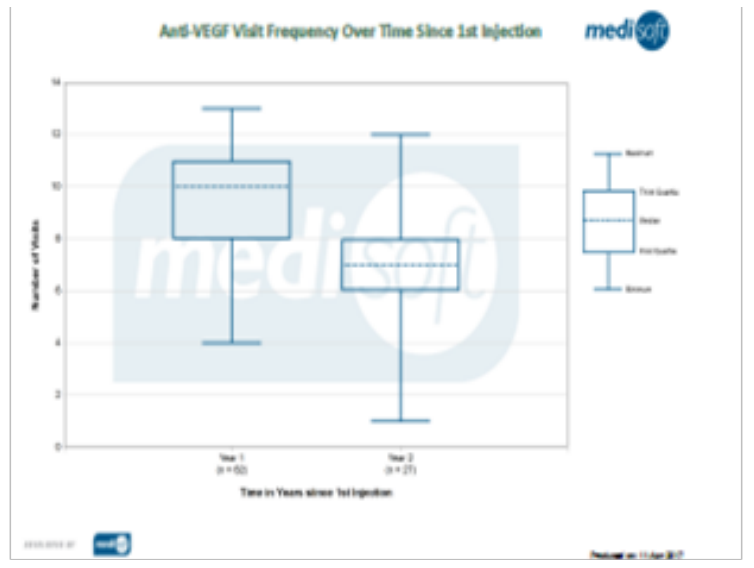

Figure 4 Visit frequency over time.

number of injections in PAH was 7 in the first year as compared to 8.4 in RETAIN and 8.3 in BRAVO (Table 1). More than half of eyes treated in PAH achieved driving vision at 30 months. Long-term outcomes of BRVO patients treated with Ranibizumab are comparable to BRAVO and RETAIN studies.

Table I Comparison of results

\section{Comparison of results from Bravo, Retain and $\mathrm{PAH}$}

\begin{tabular}{|c|c|c|c|}
\hline Criteria & Bravo & Retain & PAH \\
\hline $\begin{array}{l}\text { Improvement of } \\
\text { mean VA from } \\
\text { baseline }\end{array}$ & $\begin{array}{l}16.7 \text { letters } \\
\text { (12 months) }\end{array}$ & $\begin{array}{l}20.1 \text { letters } \\
\text { (4 years) }\end{array}$ & $\begin{array}{l}20 \text { letters } \\
\text { (35 months) }\end{array}$ \\
\hline $\begin{array}{l}\text { Frequency of } \\
\text { injections }\end{array}$ & 8.4 in $1^{\text {st }}$ year & 8.3 in $1^{\text {st }}$ year & 7 in $1^{\text {st }}$ year \\
\hline
\end{tabular}

\section{Acknowledgements}

None.

\section{Conflicts of interest}

There are no conflicts of interest.

\section{Funding}

None. 